\title{
Article \\ The Importance of Propagule Dispersal in Maintaining Local Populations of Rare Algae on Complex Coastlines: Padina pavonica on the South Coast of England
}

\author{
Roger J.H. Herbert ${ }^{1, *}$, Jay Willis ${ }^{2}(1)$ and John Baugh ${ }^{3}$ \\ 1 Faculty of Science \& Technology, Department of Life and Environmental Sciences, Bournemouth University, \\ Talbot Campus, Fern Barrow, Poole, Dorset BH12 5BB, UK \\ 2 The John Krebs Field Station, Department of Zoology, University of Oxford, Wytham, Oxford OX2 8QJ, UK; \\ jkwillis@gmail.com \\ 3 HR Wallingford Ltd., Howbery Park, Wallingford, Oxfordshire OX10 8BA, UK; j.baugh@hrwallingford.com \\ * Correspondence: rherbert@bournemouth.ac.uk
}

check for updates

Citation: Herbert, R.J.H.; Willis, J.; Baugh, J. The Importance of

Propagule Dispersal in Maintaining

Local Populations of Rare Algae on

Complex Coastlines: Padina pavonica on the South Coast of England.

Phycology 2021, 1, 1-13. https://

doi.org/10.3390/phycology1010001

Academic Editors: Saúl Blanco and José Lucas Pérez-Lloréns

Received: 8 May 2021

Accepted: 9 June 2021

Published: 28 June 2021

Publisher's Note: MDPI stays neutral with regard to jurisdictional claims in published maps and institutional affiliations.

Copyright: (c) 2021 by the authors. Licensee MDPI, Basel, Switzerland. This article is an open access article distributed under the terms and conditions of the Creative Commons Attribution (CC BY) license (https:// creativecommons.org/licenses/by/ $4.0 /)$.

\begin{abstract}
On dynamic coastlines, populations of protected algal species with poor dispersal might be especially vulnerable to infrequent recruitment events and local extinction. As a model, we here consider the dispersal of the alga Padina pavonica from the largest remaining and physically isolated enclaves on the south coast of England. A bio-physical model was used to investigate the likely importance of local propagule dispersal in maintaining populations. Dispersal kernels that simulate the position of propagules at different time steps over 5 days were examined from five release sites. Exceptionally steep declines in model propagule density were observed over the first few hours from release, yet over the first day, $75-85 \%$ of model propagules remained close to their source but had not reached other enclaves. After five days, the dispersal from source populations ranged from 0 to $50 \mathrm{~km}$, with only $5 \%$ remaining within the source $1 \mathrm{~km}^{2}$ area. Although distances of modelled propagule dispersal might be adequate for maintaining a regional population network, vegetative perrenation also appears to be important for persistence of $P$. pavonica. For rare and protected species on isolated and energetic coastlines, local conservation efforts, rather than a reliance on a wider meta-population network, remain very important to ensure long-term protection and survival.
\end{abstract}

Keywords: dispersal; connectivity; biogeography; bio-physical model; marine protected areas; Padina pavonica

\section{Introduction}

Inshore coastal ecosystems are under pressure due to rising sea temperatures, sea level rise and the risk of habitat loss due to a wide variety of anthropogenic disturbances [1-3]. There is a need to more accurately understand the dispersal and recruitment of marine organisms in an era of unprecedented change. Convoluted coastlines, with their proximate variation in the degree of wave exposure and habitat, will often be of high conservation value and there is a need to understand how populations of protected species, especially those with relatively poor means of dispersal, can persist in these areas where tidal currents can be locally very strong. The identification and maintenance of connectivity between and among populations, via reproductive propagules, is an important principle of the design of networks of marine reserves [4-9] that enable species to track environmental change [10]. Yet, advection and turbulent diffusion can be a serious constraint when investigating dispersal pathways and designing marine protected areas [11]. To identify the location of habitat barriers that might limit the recovery of degraded habitats or the expansion of a marine organisms range due to climatic changes, there is need for a much greater understanding of propagule dispersal, connectivity and species persistence especially along complex coastlines [12]. In the development of conceptual frameworks of 
propagule dispersal, theoretical studies have often made important assumptions including a homogenous distribution of adults, simple coastlines with minimal turbulence and flows $[13,14]$ or zero temporal variation of current speed and mixing [15].

Fast-flowing currents at headlands may cause an offshore dispersal of spores and other propagules that could potentially isolate already fragmented populations of intertidal species $[16,17]$. Where populations consist of small fragmented patches, an assessment of the potential reproductive connectivity within the metapopulation network may be necessary to prioritise the protection of areas that are considered important sources of propagules, such as juveniles, larvae or algal spores [9]. These areas may be important for both the replenishment of existing populations and for the potential spread of the species through longer-distance dispersal.

The distances at which propagules (spores and vegetative fragments) could potentially disperse is extremely wide ranging from just a few metres to thousands of kilometres $[14,18,19]$ and the scale of dispersal of any taxon will vary spatially and temporally $[4,14,20]$. Although knowledge and understanding are growing [18,19], the dispersal capabilities of most species are still relatively unknown. Long-distance dispersal (LDD) [14] has been defined as those individual propagules that travel much further than the mean or 'bulk', either by getting caught in strong currents, as a result of extreme weather, including storms or wave turbulence, and therefore may remain in the water column for extended periods. Yet, a growing consensus is that, for a wide variety of taxa, local replenishment of populations is the norm, with most propagules being dispersed into and recruiting from 'local waters', i.e., within such proximity of adults so to potentially influence population demography. For example, the survival of the sea palm Postelsia palmaeformis (Ochrophyta, Phaeophyceae) is dependent on short-distance dispersal, although occasional long-distance dispersal must occur that could explain colonisation of new sites [21].

There has been very little progress regarding the conservation status of marine algae [22], although see [23]. Few studies have investigated potential population connectivity of intertidal algae on complex coastlines. Unlike animals, the propagules of most macroalgae are competent immediately upon release or within a few days and yet there are many factors that determine their duration and depth within the water column, including water turbulence and size and shape that can affect sinking speed [24-26]. Although the duration of algal spores in the water column has been estimated as less than one day, spore survival can be considerably longer $[24,26]$. The height of propagule release above the seabed and the sinking speed of spores are particularly important $[15,27]$. Both these parameters were found to be theoretically influenced by current speed and wave height, which characterise turbulence within the coastal zone.

Due to their small size, there are inherent difficulties of tracking and collecting spores, larvae and other propagules in the open sea [28-30] and verification of transport pathways is difficult. Improved bio-physical models have now become more widely available which enable the tracking of model propagules in more complex environments that can provide estimates of dispersal of protected and invading species [31,32].

\section{Padina pavonica}

The alga Padina pavonica (L.) Thivy (Ochrophyta, Phaeophyceae) is one of several scarce species of 'low mobility' that have been selected for inclusion within a network of Marine Conservation Zones (MCZ) in England [33,34]. P. pavonica is the type species of the genus and has been reported from the North-East Atlantic European coast, South Atlantic, Indian Ocean, Pacific, and the Mediterranean [35]. Although Mediterranean populations occur subtidally, on the south coast of England where the species is at the northern limit of its geographical range, enclaves may only be found intertidally on rocky shores [36,37]. The species has a haplodiplontic, isomorphic life cycle, but sexual plants, whether male or female, are very rarely reported $[36,38,39]$. P. pavonica is a low-growing alga (maximum clump height in water $\sim 10 \mathrm{~cm}$ ) and on the English coast, multiple releases of non-motile asexual tetraspores occur during the main reproductive period between May 
and September. Although lunar periodicity of gamete release has been shown for some species of Dictyotales [40-42], this remains unconfirmed in Padina spp.

With other species of low or limited mobility, the spatial strategy in England to maintain connectivity of $P$. pavonica is for populations to be included within protected areas of minimum patch size diameter $0.5 \mathrm{~km}$ and which are not more than $40-80 \mathrm{~km}$ distant from other protected populations [34,43]. Currently, all of the Padina enclaves on the Isle of Wight fall within this distance range and are within two European (Natura 2000) Special Areas of Conservation (SAC) and designated or proposed Marine Conservation Zones (MCZs). However, it is of interest to establish evidence for potential connectivity both within and between the potentially vulnerable and fragmented populations remaining within this tidally dynamic and complex coastline. For species at the periphery of their geographic range, bio-physical models may be more helpful than genetic studies as populations may not be as reproductively active as those from the range centre [44-46], and therefore reproductive connectivity through genetic analyses of adults may not yield information on pathways of dispersal.

Given the tidally dynamic nature of the region, the aim of this study is to establish the probability that local existing population enclaves on the Isle of Wight could be regularly replenished by local and regional dispersal, i.e., dispersal distance less than the mean.

\section{Materials and Methods}

\subsection{Study Area}

The Isle of Wight on the south coast of England (Figure 1) has five of the largest enclaves of Padina pavonica remaining in the British Isles and these are located at sites with varied wave exposure and substratum [37,47]. These populations have been known for over a century and herbarium material has been deposited in the Natural History Museum (London) [36,47]. To date, species identification has been based only on morphological characteristics, yet with ongoing research into the genus, it is possible that taxonomy of English populations and others on the North-East Atlantic will be revised [35]. Padina on the south coast of England are usually attached to the bottom and sides of rock pools, normally in the middle and lower shore zones. The regional hydrodynamics of this coast are complex [48,49]. The tidal range in the west of the Solent is between 2 and $3 \mathrm{~m}$, and this increases to $4 \mathrm{~m}$ in the east. There are strong west-east tidal streams $\left(\max 3 \mathrm{~ms}^{-1}\right)$ and the water is well mixed. The region also experiences a double stand at high water on spring tides and a gyre is located offshore in the east of the Isle of Wight [17]. Prevailing wind direction is south-west, so the enclaves of $P$. pavonica are on exposed or moderately exposed shores. Mean salinity at Padina enclaves is $34 \%$ and sea temperature range is $6-19^{\circ} \mathrm{C}$. The Solent region has a considerable urban population and infrastructure, and pollution and other disturbances pose a risk to remaining enclaves of Padina.

\subsection{Water Model Particle Tracking Model}

We used well established methods for running a Lagrangian particle model where the velocity at any point is interpolated in space and time from the output of a numerical hydrodynamics model [31,32]. Here, we briefly describe the hydrodynamic model and then the Lagrangian particle model run from the output of the hydrodynamic model.

Hydrodynamic conditions in the study area (Figure 1) were simulated using the twodimensional (2D), depth-averaged flow model TELEMAC-2D (http:/ / www.opentelemac. $\mathrm{org} /$, accessed on 10 June 2021). We used an existing 2D hydrodynamic model that was built for planning and other commercial purposes by HR Wallingford Ltd. (Wallingford, UK). The water model was built to well-established engineering tolerances and had been calibrated using a variety of existing and newly surveyed bathymetric and flow data (see ref. [31] and references therein for an explanation of the type of water model and its application). The spatial resolution of the unstructured triangular mesh used by the model is variable between 100 and $2000 \mathrm{~m}$. The water model was run 'off-line' for a full spring-neap tidal cycle and the velocity and depth results at $1400 \mathrm{~s}$ time steps were saved. 
This is an appropriate increment for saving the output of a tidal hydrodynamic model; it is an arbitrary choice but has been shown to capture all the essential dynamic features of a tidal cycle, and this can be checked directly during operation of the water model, which typically uses a $1 \mathrm{~s}$ internal time step [31]. In order to allow the hydrodynamic model results to be used over any period of time, starting at any point in the tidal cycle, the results file data were looped using the following method. An arbitrary start time (after the model had stabilised (run-in) was chosen, and then the hydrodynamic model output was run through the entire spring-neap cycle while depths were interpolated from the data in space and time and recorded at set of three reference points. The reference points were chosen arbitrarily to represent positions across the entire model area and an end time was chosen when the tide had returned as close as possible to a similar state at all three sites simultaneously. By referencing (connecting) the data at the end time back to the start time, the hydrodynamic data could be looped continually through endless similar spring-neap cycles. This method is computationally efficient in comparison to running a particle model at the same time as the water model and is functionally identical.

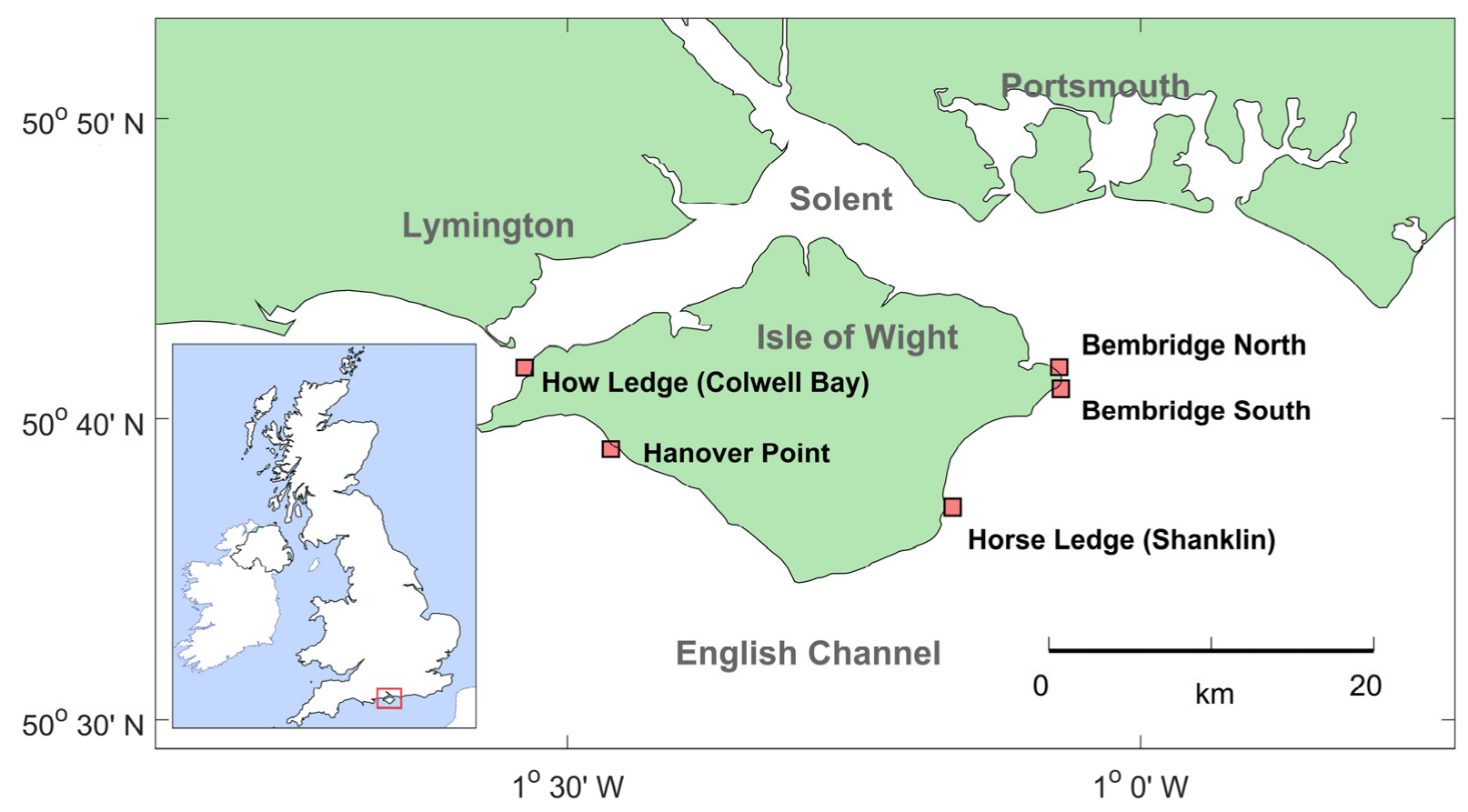

Figure 1. The Isle of Wight on the south coast of England showing main enclaves of P. pavonica: Colwell, Hanover Point, Shanklin, Bembridge south, Bembridge north. These locations also represent the release sites of propagules in the model.

A Lagrangian particle model was run using the output from the hydrodynamic model as the basis for movement of the particles. The time step of the Lagrangian particle model was $100 \mathrm{~s}$, although the results were saved at longer intervals $(1 \mathrm{~h})$. It is common practice to use shorter time steps for the particle model in comparison to the results of the hydrodynamic model. Since the velocity at any position, at any time, across the modelled area and time period can be interpolated from the water model results it is possible to choose any time step for the Lagrangian model independently of the water model [31,32].

We chose to model a number of scenarios (of particles been released from various places at various times during the tidal cycle). For each scenario, 2500 propagules were released from each intertidal site at high tide over a spring tide cycle from a $1 \mathrm{~km}^{2}$ zone (Figure 1). The particles were initially uniformly randomly distributed in the release area, and their start times were uniformly randomly distributed in a $2 \mathrm{~h}$ period centred on the time of a spring high tide. This is standard practice to ensure the results sample a range of potential exact start times and places. Each particle then takes a slightly different route through the model, dependent on the precise start time and position within the release area 
and time. This is also determined by the parameters of several correlated random walks which are used to model turbulence below the spatial resolution of the water model. We used fourth-order Runge Kutta integration and a separate short vertical time step (10 s) to model realistic dispersion of particles (sub grid scale turbulence), and we used logarithmic velocity profile with depth (the law of the wall). These are well established methods that have been verified and calibrated in coastal tidal situations and in shallow channels over many years [31]. Where results of a single run were numerically low, multiple runs of $10 \times 2500$ particles were used to give better resolution of uncertainty; this is the standard method to characterise the probabilistic results of particle dispersion models [50]. The model propagules remained in the model for the 5 model days, during which their positions every hour were recorded.

In order to represent the dispersion of the modelled particles as a surface rather than a series of discrete points we summed their positions across a square spatial grid. It is important not to limit the results to a single time, because the tidal cycle means that particles repeatedly cover a range of space, so the results are visualised by using all the positions of the particles over an extended time period-in this case, we used the entire 5 day run of the model. When all the positions are allocated to similar area grid spaces, the resultant numbers represent a probability that any particle would be found in that grid space at any time during the modelled period. Thus, when normalised, the surface is formally a probability density kernel representing the probability of dispersion to each grid square. The individual probabilities across the grid are arbitrarily scaled by the granularity of the grid and are usually very small values, but this is irrelevant as long as the results are compared over a similar probability grid. We have found that, in visualisation, a log transformation of the results makes comparisons more meaningful as areas with very small probability values are enhanced in comparison to higher-density areas. Thus, the geographic figures scale probabilities in log-transformed values to display the probability density kernels.

\section{Results}

For the first $24 \mathrm{~h}$, dispersive tidal currents initially reduce the density of propagules at release sites very steeply (power function), which is well modelled from all sites and illustrated for Bembridge (Figure 2). Over the first day, 75-85\% of model propagules remained close to their source, but had not reached other enclaves. Yet, towards the end of the five-day model run, an exponential function is a better fit overall (Figure 3).

Perhaps the most informative model of dispersion is a fast-moving but very low density front which can move along the coast from 5 to $20 \mathrm{~km}$ per day, and which may be symmetrical or fully asymmetrical depending on tidal ellipse, as shown in the contour figures (Figures 4 and 5). After five days (Figure 6), the dispersal from source populations ranged from 0 to $50 \mathrm{~km}$ and approximately $4 \%$ of the model propagules still remained within (or had returned to) each of the release zones. Potential connectivity was mainly from within existing enclaves and west to east, but not east to west.

The smallest enclave in Colwell Bay connected with most sites yet was itself isolated. Propagules from Colwell dispersed largely to the east although the distribution is bimodal, with one group between 6 and $8 \mathrm{~km}$ and another between 30 and $40 \mathrm{~km}$ from the release zone (Figure 7). Of all sites, propagules from both Bembridge North and South stayed closest to the release zones $(8-10 \mathrm{~km})$. The propagules released from Hanover Point achieved the greatest mean distance of any site. Overall, all sites connect relatively well with themselves (Figure 8). Both Bembridge sites connect well with each other and locally with Shanklin, though not between the western sites (apart for a single propagule at Colwell from Bembridge South). 


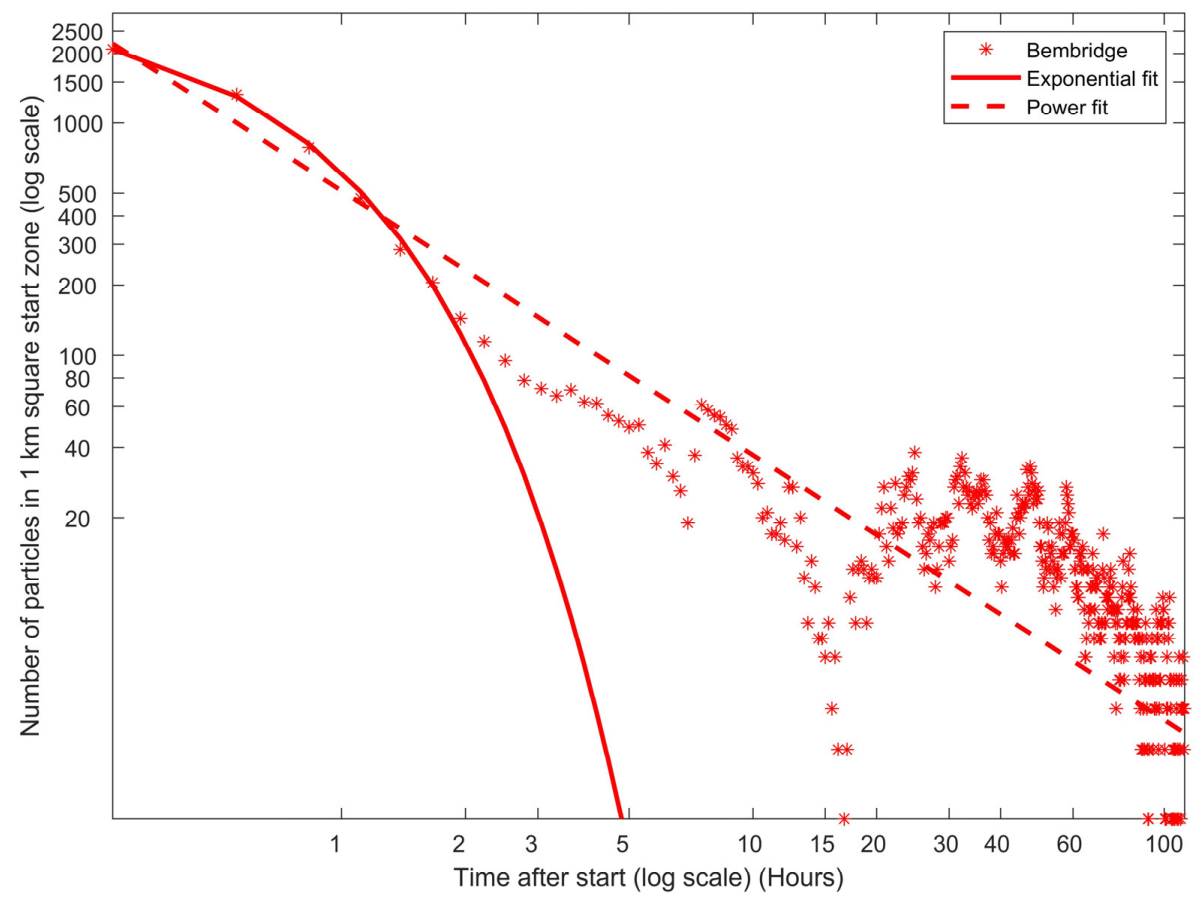

Figure 2. Number of model propagules in $1 \mathrm{~km}$ square zone at Bembridge from start of model run for $100 \mathrm{~h}$. Note that for the first $24 \mathrm{~h}$, dispersal is best fitted by a power function, whereas a general exponential fit is appropriate after this period.

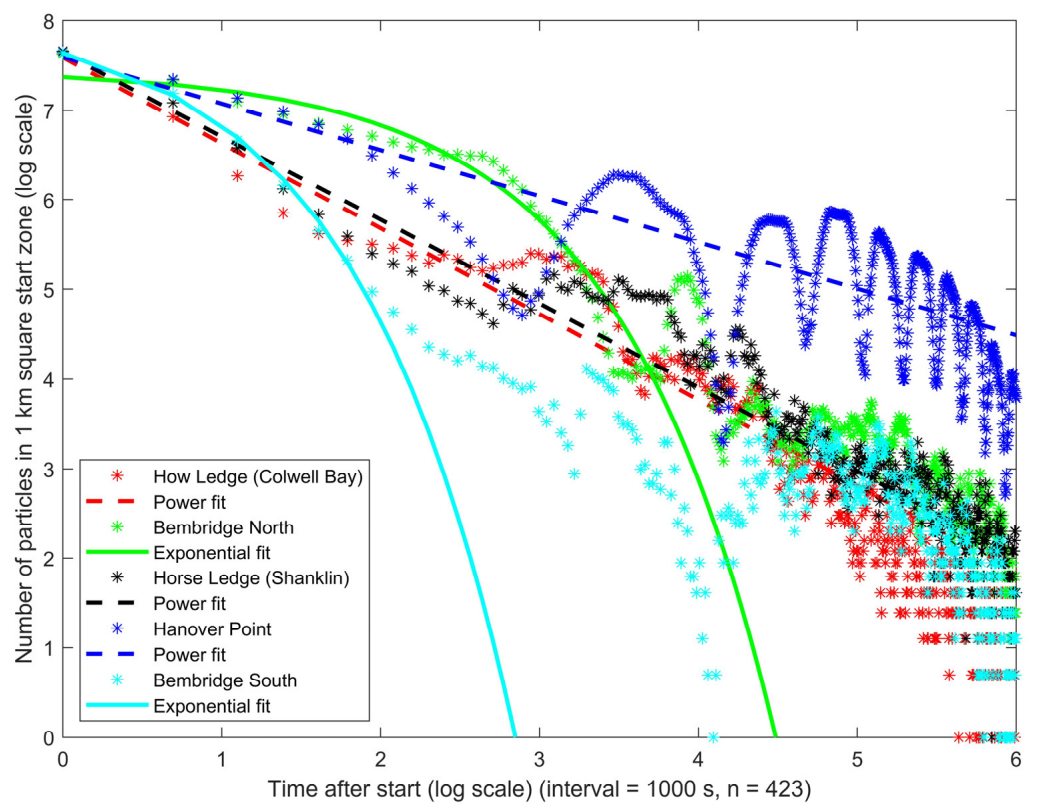

Figure 3. Number of particles in start zone against time since release. Time step $=1000 \mathrm{~s}$, over 5 days. Power or exponential fit chosen by maximum likelihood. A total of 2500 released randomly over $8 \mathrm{~h}$ period starting at spring high tide (therefore time data here not concurrent with actual time but different start for each particle). The tidal pattern in all groups is most evident in the particles released at Hanover Point. Since the coastline at this location is comparatively more geographically linear than the other sites, some particles are retained in a higher-density group and thus a higher proportion of these return to the start zone, with each tide, in a more coordinated pattern. This effect is consistent with the patterns which can be compared between the sites in the other figures. The fits to power law or exponential function relate to general theories of dispersal discussed in the text. 


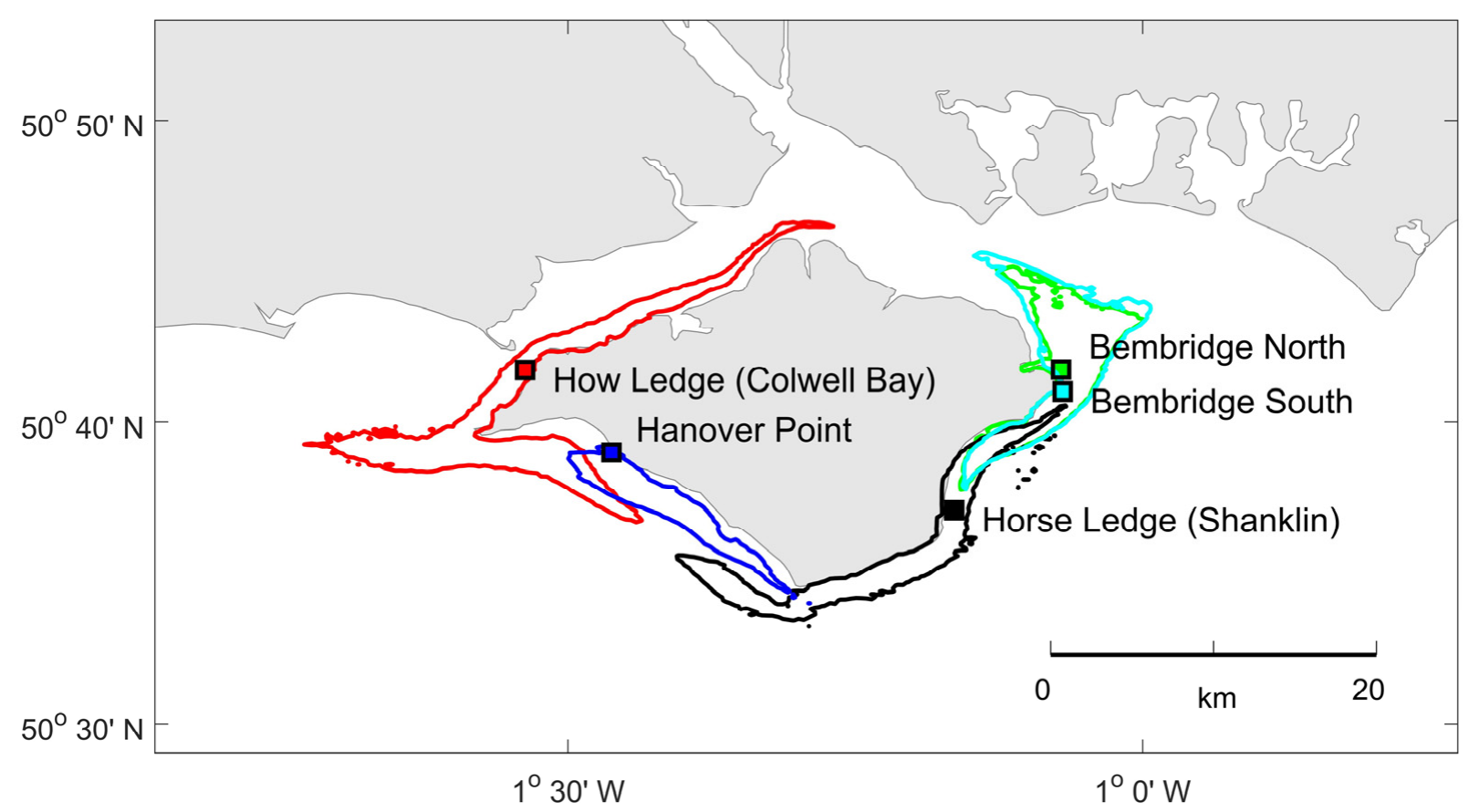

Figure 4. Contours at -9.5 from log-transformed probability density kernels. Contours contain from 75 to $85 \%$ of all $200 \mathrm{k}$ positions for each release zone over first day.

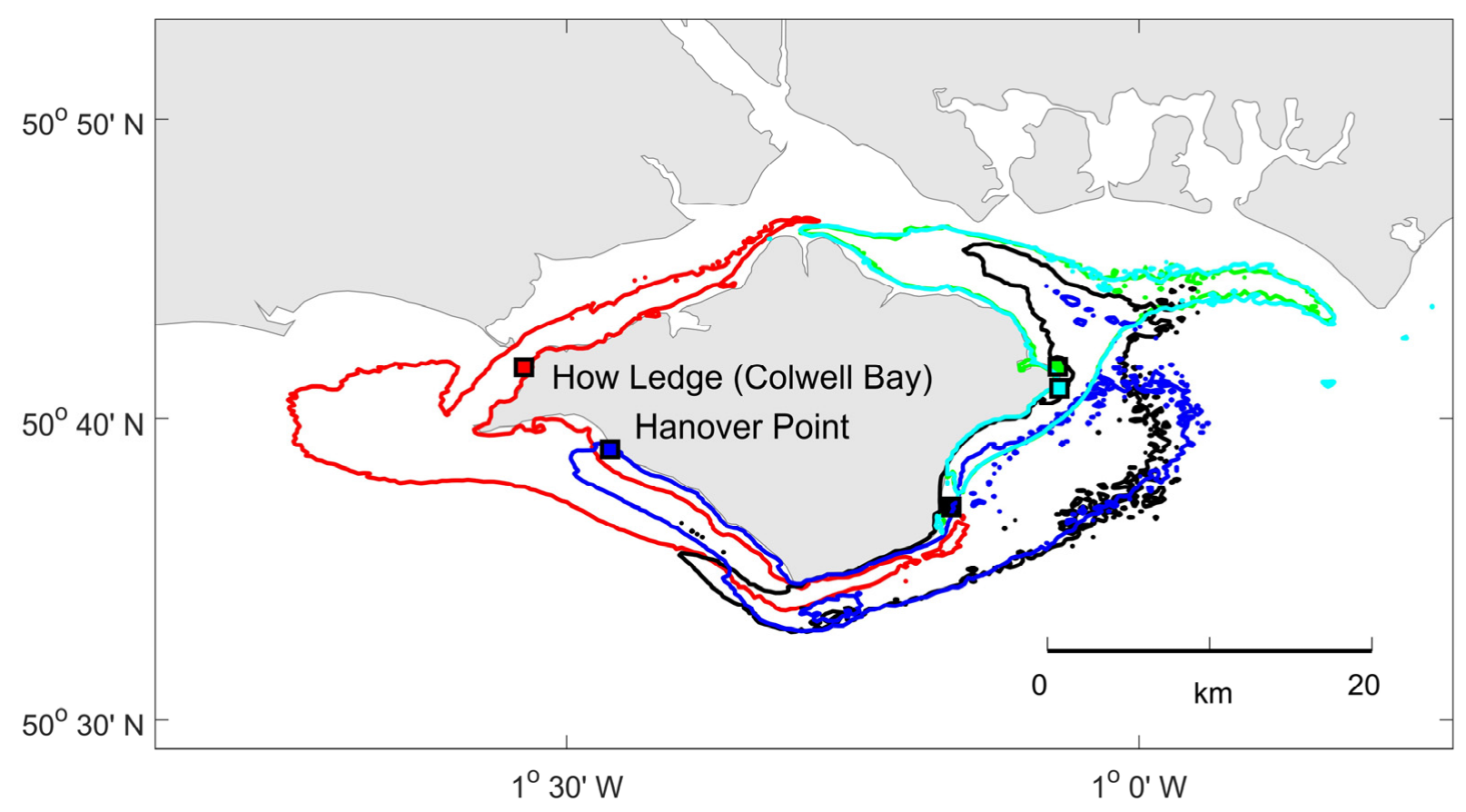

Figure 5. Contours at -9.5 from log-transformed probability density kernels. Contours contain from 75 to $85 \%$ of all 1 million positions for each release zone over full 5 days. Shows connectivity from western to eastern zones and among eastern zones, but not from eastern to western zones. 

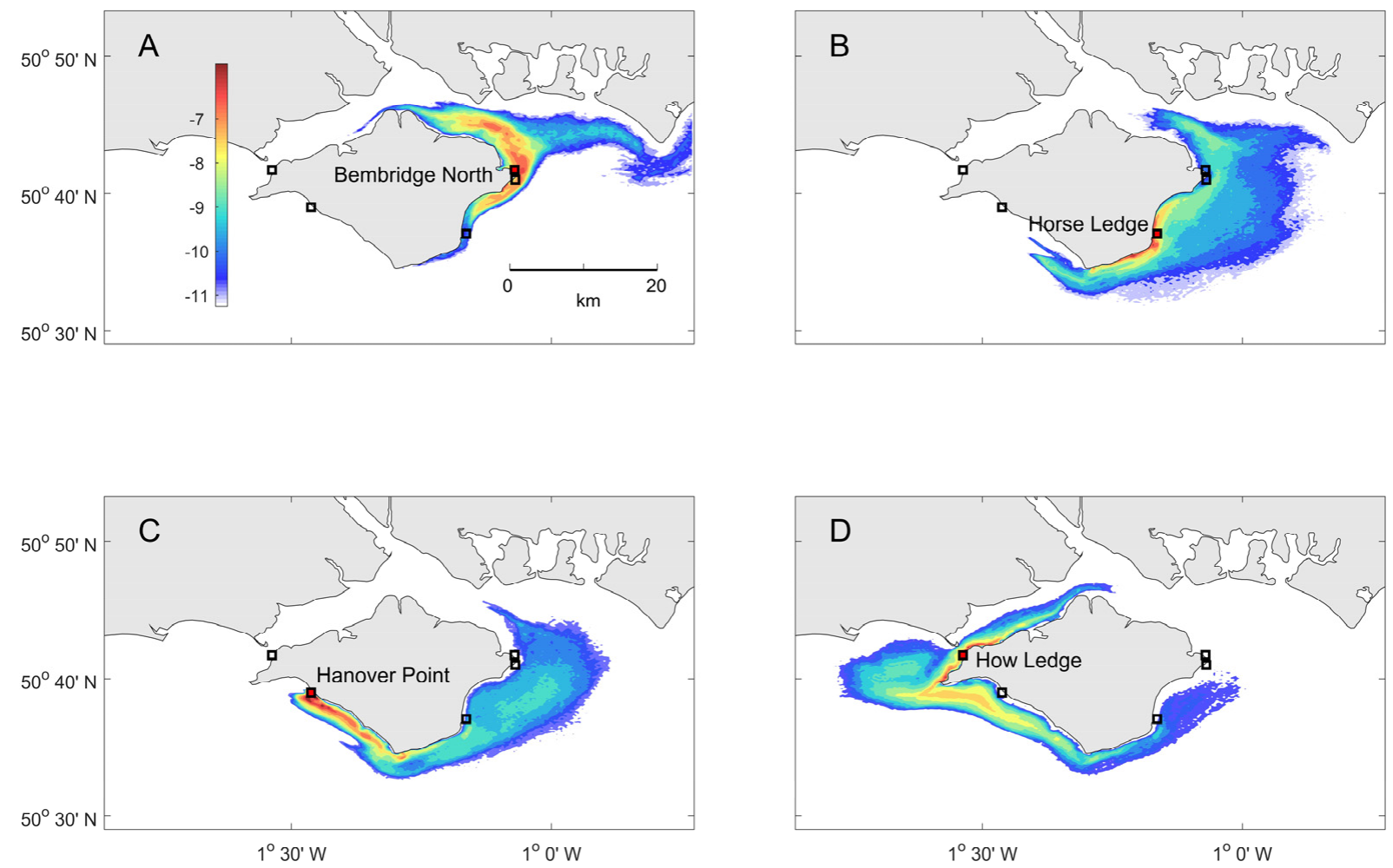

Figure 6. The 5-day dispersal kernals for model propagules (asexual tetraspores, sexual spores and vegetative fragments) of P. pavonica released during spring tides from sites on the Isle of Wight, south coast of England: (A) Bembridge, (B) Shanklin, (C) Hanover Point and (D) Colwell.

The histograms of Colwell Bay especially and the Bembridge sites to a lesser degree show a bimodal pattern which is consistent with their positions on the extreme east and west of the island (Figure 7). The dominant tidal excursion at this overall location is east-west and so these positions on the headlands allow particles to travel both to either the north and south of the island, or away from the coast, in which areas dispersions are markedly different, whereas the other two sites are both on the more exposed and geographically linear southern shores and so their dispersion is overall further and more unimodal, with Hanover point being the extreme of this pattern. Note that Hanover Point shows least number of spores eventually retained closest to source which is a contrast to the pattern in Figure 3. This is explained by the retention of a group of particles in a linear pattern near Hanover Point. A high proportion of this minority are drawn back into the start zone at each tidal cycle, which again is consistent with the location of other sites where, in contrast, local dispersion near the release zones was more diffuse.

There was no evidence of dispersal west of the study area beyond the boundaries of the existing model and towards other extant populations $40 \mathrm{~km}$ to the west [37]. However, a very light eastwards dispersal of model propagules is evident towards location of former populations in the eastern Channel. 

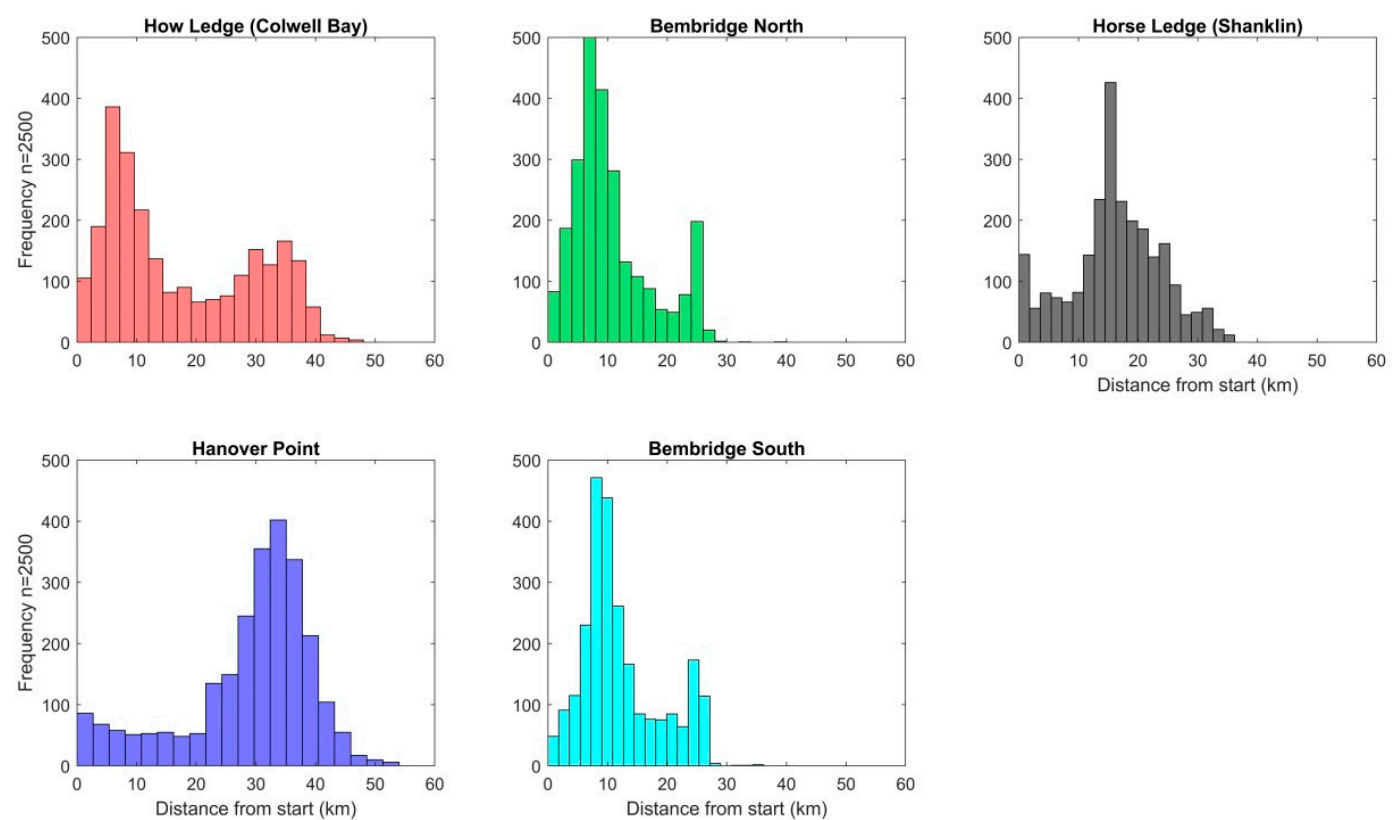

Figure 7. Histograms of distance away frequency for $n=2500$ particles on final step after 5 days at liberty. Some model boundary edge interaction is evident in Bembridge $\mathrm{N}$ and $\mathrm{S}$. Note that Hanover Point shows least number of spores closest to source. (The colours of the histograms are consistent with those used in Figures $2-5$ for the different sites.)

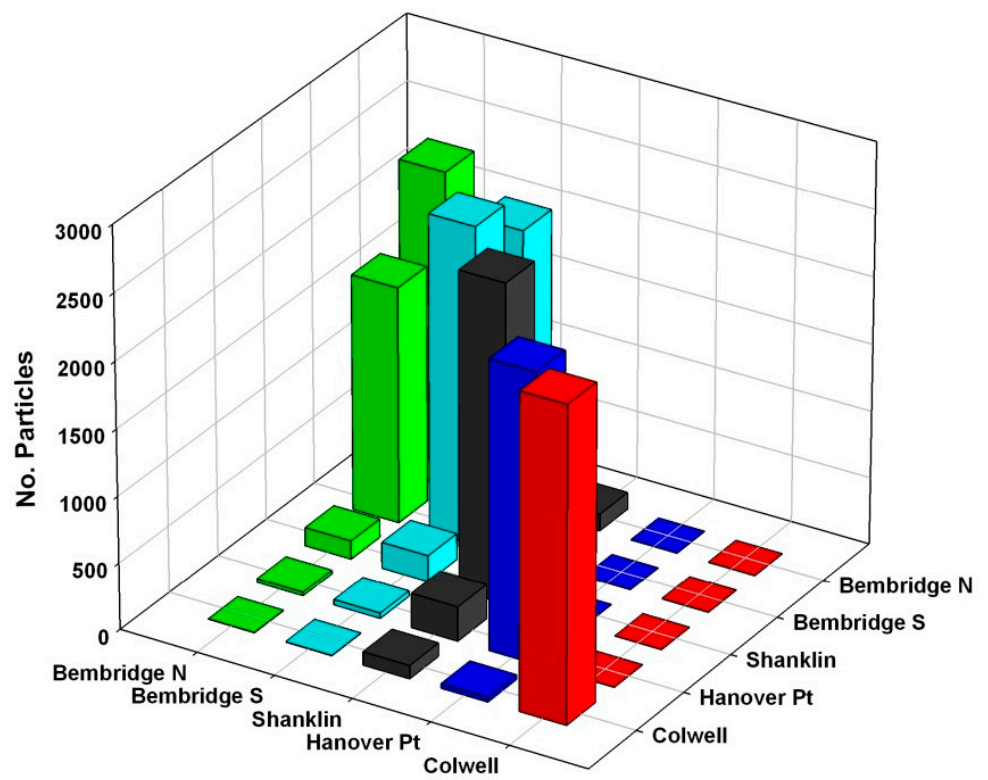

Figure 8. Matrix bar chart showing potential connectivity of sites over 5 days after the first time step. Particles ( $n=2500$ from each site) released from model and the potential connectivity between existing populations (from right axis to bottom axis). (The colours of the histograms are consistent with those used in Figures $2-5$ and 7 for the different sites.)

\section{Discussion}

Even along a highly dispersive and hydrodynamically active coastline, the model reveals that over the first $24 \mathrm{~h}$ a relatively high proportion of released propagules are retained in proximity to release sites. However, after five days, the recruitment matrix does not connect well with non-source enclaves. Very few propagules travelled beyond the boundaries of the model, and therefore the Isle of Wight region, although tidally highly dynamic, appears 'regionally closed' and does not connect with the mainland coast to 
the north and other extant populations of Padina on rocky shores to the west or former populations to the east. Given that the Isle of Wight populations of Padina are the largest in the British Isles, we cannot assume that they can supply propagules to replenish other local sites on the island or the small remaining extant enclaves to the west.

Even though the bulk of macroalgal propagules are considered to hit the sea bed and potentially 'settle' within 1-10 m of release, a substantial fraction could also theoretically disperse much greater distances, even for low-growing species [15]. However, there is considerable uncertainty in relation to the extent to which propagules get beyond the shore and into tidal streams. Although the sinking rate of large tetraspores is considered to be relatively high, author's attempts to capture Padina tetraspores in situ with spore traps have so far failed, even when they are placed beneath clumps of fronds. Yet, from an examination of the tetrasporangial rings, spores are released from these colonies [37]. There may be sufficient variation in vertical distribution of propagule depth to affect their modelled spatial distribution [51]. Drift plants and frond fragments are not commonly seen on shores around extant populations on the south coast of England. Yet, on the shores of Malta in the Mediterranean, where the genus can be abundant, Padina fronds are washed up from large subtidal populations in such quantities to cause a nuisance on bathing beaches and tetraspores can achieve visibly high densities in the water column (C. Saliba personal communication).

Given that mortality of live propagules in the water column is high, their density and distribution in the water column will become less with duration and therefore likely to be significantly reduced after five days [26]. The settlement of algal spores is precarious and the actual magnitude of recruitment is also difficult to assess [52]. Field observations on the Isle of Wight reveal that small isolated clumps with few fronds are prevalent in all enclaves and are assumed to have grown as a result of more recent settlement [36] p. (46). However, uncertainty remains. In tropical/sub-tropical locations where Padina spp. are more dominant, it has been possible to estimate new recruitment from substrate clearances made prior to settlement [53]. However, where the species is rare and protected, this is both ineffective and unethical. From dGPS mapping of Isle of Wight populations, it is known that small clumps of fronds appear in new places each year [47]. Here, perennation and vegetative spread appear to be important in maintaining populations during less favourable periods and fronds may grow sporadically from an established rhizoid mass within the substratum [36,54]. For the conservation of species on highly dispersive coastlines, where connectivity within the population network may be low or relatively infrequent, this life history strategy is particularly important.

The current distribution of P. pavonica is considered to extend from the Mediterranean, north along the Atlantic coast to the English Channel [35-37]. In northern Europe, there is circumstantial evidence that populations once occupied the shores of the Netherlands and Belgium and an analysis of the historical record has revealed a probable range contraction that also included populations in the eastern English Channel [36]. Dispersal occurs at a wide range of scales in marine communities and yet because it is impossible to incorporate stochastic and extreme events within bio-physical models, the likelihood that the species could spread beyond remaining populations on the south coast of England and recolonise former sites in the eastern English Channel must be speculative. However, dispersal eastward of the Isle of Wight is evident from the model (Figure 4). For a species that is at the periphery of its range, the possibility of expanding its distribution should be considered, as if conditions ameliorated, there may be a longer reproductive season and an overall greater fecundity that may increase the probability of long-distance dispersal of spores or tetraspores. Incorporation of wind speed and direction to the models would be useful. However, the strong tidal streams in this region are likely to be the dominant vector. In this study, the model was allowed to run for five days to capture a range of conditions over a spring tide when spores are most likely released. Multiple spore releases between May and September will coincide with a range of tidal conditions and this could be important for the species persistence in tidally dynamic coastlines such as the Solent. In the colder upwelling 
waters of northern Portugal, where there is a biogeographical discontinuity, there appears to have been a significant northward extension $(187 \mathrm{~km})$ of $P$. pavonica since the mid-20th century, which has been attributed to a rise in sea and air temperatures and long-distance dispersal along this coast [55]. The increase in size of extant populations and probability of range extension during more favourable environmental conditions in warmer years is likely to be a result of a longer reproductive period.

The dispersal of spores from other species may behave differently as size and volume vary considerably [26]. For species with greater spore longevity, model runs should reflect duration within the water column, although the motility is unlikely to stem the strong currents commonly experienced around complex coastlines.

Climate warming may now begin to arrest population decline and populations of Padina may increase due to a longer reproductive period and higher level of spore output, as have other southern, warm-temperate species on rocky shores in the British Isles [56]. However, other climatic factors, such as extreme storm events may reduce population extent [37]. Populations of P. pavonica that occur $40 \mathrm{~km}$ to the west of the Isle of Wight are now protected within a newly designated marine protected area. However, they are effectively isolated from the largest populations, at least in terms of any frequent population replenishment. As dispersal is mostly orientated towards the eastern enclaves on the Isle of Wight the smaller, western populations at Colwell and Hanover Point are more vulnerable and therefore may warrant greater protection.

Wild algal populations are at risk from numerous stressors including harvesting, trampling and bioprospecting and climate change, and therefore local and regional conservation efforts, including education programmes and on-site interpretation to highlight the species protected status, remain very important [57-59].

\section{Conclusions}

In a complex and dispersive environment with fast offshore currents, even propagules of species of low mobility might be assumed to be broadcast widely across large distances and a range of suitable habitat. Although distances of modelled propagule dispersal might be considered adequate for maintaining a regional population network, for P. pavon$i c a$, on the south coast of England, vegetative perrenation also appears to be important. For protected species of poor dispersal ability on isolated and energetic coastlines, local conservation efforts, rather than a reliance on a wider meta-population network, remain important to ensure long-term protection and survival.

Author Contributions: Conceptualisation, R.J.H.H. and J.W.; methodology, J.W. and J.B.; validation, J.W. and J.B. formal analysis, J.W.; investigation, R.J.H.H. and J.W.; resources, J.B.; writing-original draft preparation, R.J.H.H.; writing—review and editing R.J.H.H., J.W. and J.B.; project administration, R.J.H.H.; funding acquisition, R.J.H.H. All authors have read and agreed to the published version of the manuscript.

Funding: The work was supported through a grant received from the Porcupine Marine Natural History Society and SITA.

Institutional Review Board Statement: Not applicable.

Informed Consent Statement: Not applicable.

Data Availability Statement: The data presented in this study are available on request from the corresponding author. The data are not publicly available due to corporate proprietary data ownership and owner's usage restrictions.

Acknowledgments: The authors thank all field surveyors.

Conflicts of Interest: The authors declare no conflict of interest. 


\section{References}

1. Aeroldi, L.; Beck, M.W. Loss status and trends for coastal marine habitats of Europe. Oceanogr. Mar. Biol. 2007, 45, $345-405$.

2. Hawkins, S.J. Marine conservation in a rapidly changing world. Aquat. Conserv. Mar. Freshw. Ecosyst. 2012, 22, 281-287. [CrossRef]

3. Sala, E.; Mayorga, J.; Bradley, D.; Cabral, R.B.; Atwood, T.B.; Auber, A.W.; Costello, C.; Ferretti, F.; Friedlander, A.M.; Gaines, S.D.; et al. Protecting the global ocean for biodiversity, food and climate. Nature 2021, 592, 397-402. [CrossRef] [PubMed]

4. Cowen, R.K.; Lwiza, K.M.M.; Sponaugle, S.; Paris, C.B.; Olson, D.B. Connectivity of marine populations: Open or closed? Science 2000, 287, 857-859. [CrossRef] [PubMed]

5. Cowen, R.K.; Paris, C.B.; Srinivasan, A. Scaling and connectivity in marine populations. Science 2006, 311, 522-527. [CrossRef]

6. Cowen, R.K.; Sponaugle, S. Larval dispersal and marine population connectivity. Annu. Rev. Mar. Sci. 2009, 1, 443-466. [CrossRef]

7. Palumbi, S.R.; Gaines, S.D.; Leslie, H.; Warner, R.R. 2003. New wave: High-tech tools to help marine reserve research. Front. Ecol. Environ. 2003, 1, 73-79. [CrossRef]

8. Roberts, C.; Andelman, S.; Branch, G.; Bustamante, R.; Castilla, J.C.; Dugan, J.; Halpern, B.; Lafferty, K.; Leslie, H.; Lubchenco, J.; et al. Ecological criteria for evaluating candidate sites for marine reserves. Ecol. Appl. 2003, 13, 199-214. [CrossRef]

9. Coleman, M.A.; Chambers, J.; Knott, N.A.; Malcolm, H.A.; Harasti, D.; Jordan, A.; Kelaher, B.P. Connectivity within and among a network of temperate marine reserves. PLoS ONE 2011, 6, e20168. [CrossRef]

10. Fredston-Hermann, A.; Gaines, S.D.; Halpern, B.S. Biogeographic constraints to marine conservation in a changing climate. Ann. N. Y. Acad. Sci. 2018, 1429, 5-17. [CrossRef]

11. Roberts, C.M. Connectivity and management of Caribbean coral reefs. Science 1997, 278, 1454-1457. [CrossRef]

12. Sale, P.F.; Cowen, R.K.; Danilowicz, B.S.; Jones, G.P.; Kritzer, J.P.; Lindeman, K.C.; Planes, S.; Polunin, N.V.C.; Russ, G.R.; Sadovy, Y.J.; et al. Critical science gaps impede use of no-take fishery reserves. Trends Ecol. Evol. 2005, 20, 74-80. [CrossRef]

13. Crisp, D.J. The spread of Elminius modestus Darwin in north-west Europe. J. Mar. Biol. Assoc. UK 1958, 37, 483-520. [CrossRef]

14. Kinlan, B.P.; Gaines, S.D.; Lester, S.E. Propagule dispersal and scales of marine community process. Divers. Distrib. 2005, 11, 139-148. [CrossRef]

15. Gaylord, B.; Reed, D.C.; Raimondi, P.T.; Washburn, L.; McLean, S.R. A physically based model of macroalgal spore dispersal in the wave and current dominated nearshore. Ecology 2002, 83, 1239-1251. [CrossRef]

16. Herbert, R.J.H.; Southward, A.J.; Clarke, R.T.; Sheader, M.; Hawkins, S.J. Persistent border: An analysis of the geographic boundary of an intertidal species. Mar. Ecol. Prog. Ser. 2009, 379, 135-150. [CrossRef]

17. Keith, S.A.; Herbert, R.J.H.; Norton, P.A.; Hawkins, S.J.; Newton, A.C. Individualistic species limitations of climate induced range expansions generated by meso-scale dispersal barriers. Divers. Distrib. 2011, 17, 275-286. [CrossRef]

18. Shanks, A.L. Pelagic larval duration and dispersal distance revisited. Biol. Bull. 2009, 216, 373-385. [CrossRef]

19. Shanks, A.L.; Grantham, B.A.; Carr, M.H. Propagule dispersal distance and the size and spacing of marine reserves. Ecol. Appl. 2003, 13, 159-169. [CrossRef]

20. Cowen, R.K.; Paris, C.B.; Olson, D.B.; Fortuna, J.L. The Role of Long Distance Dispersal Versus Local Retention in Replenishing Marine Populations. Gulf Caribb. Res. 2003, 14, 129-137. [CrossRef]

21. Paine, R.T.; Buhle, E.R.; Levin, S.A.; Kareiva, P. Short-range dispersal maintains a volatile marine metapopulation: The brown alga Postelsia Palmaeformis. Ecology 2017, 98, 1560-1573. [CrossRef]

22. Brodie, J.; Anderson, R.A.; Kawachi, M.; Millar, A.J.K. Endangered algal species and how to protect them. Phycologia 2009, 48, 423-438. [CrossRef]

23. Maneiro, I.; Couceiro, L.; Barbara, I.; Cremades, J.; Ruiz, J.M.; Barreiro, R. Low genetic variation and isolation of northern peripheral populations of a red seaweed (Grateloupia lanceola). Aquat. Conserv. Mar. Freshw. Ecosyst. 2011, 21, 590-600. [CrossRef]

24. Santelices, B. Patterns of reproduction, dispersal and recruitment in seaweeds. Oceanogr. Mar. Biol. 1990, $28,177-276$.

25. Norton, T.A. Dispersal by macroalgae. Br. Phycol. J. 1992, 27, 293-301. [CrossRef]

26. Maggs, C.A.; Callow, M.E. Algal Spores. In Encyclopedia of Life Sciences; Macmillan Publishers Ltd., Nature Publishing: London, UK, 2002; pp. 1-6.

27. Gaylord, B.; Reed, D.C.; Raimondi, P.T.; Washburn, L. Macroalgal spore dispersal in coastal environments: Mechanistic insights revealed by theory and experiment. Ecol. Monogr. 2006, 76, 481-502. [CrossRef]

28. Gawarkiewicz, G.; Monismith, S.; Largier, J. Observing larval transport processes affecting population connectivity: Progress and challenges. Oceanography 2007, 20, 40-53. [CrossRef]

29. Pineda, J.; Hare, J.; Sponaugle, S. Larval Transport and Dispersal in the Coastal Ocean and Consequences for Population Connectivity. Oceanography 2007, 20, 22-39. [CrossRef]

30. Watson, J.R.; Mitarai, S.; Siegel, D.A.; Caselle, J.E.; Dong, C.; McWilliams, J.C. Realized and potential larval connectivity in the Southern Californian Bight. Mar. Ecol. Prog. Ser. 2010, 401, 31-48. [CrossRef]

31. Willis, J. Modelling swimming aquatic animals in hydrodynamic models. Ecol. Model. 2011, 222, 3869-3887. [CrossRef]

32. Swearer, S.E.; Treml, E.; Shima, J.S. A Review of Biophysical Models of Marine Larval Dispersal. In Oceanography and Marine Biology: An Annual Review; Hawkins, S.J., Allcock, A.L., Bates, A.E., Firth, L.B., Smith, I.P., Swearer, S.E., Eds.; CRC Press: Boca Raton, FL, USA, 2019; Volume 57, pp. 325-356.

33. Joint Nature Conservation Committee. UK BAP Priority Species 2007. Padina pavonica (Linnaeus) Thivy Peacock's Tail. v2 2010a. Available online: https://jncc.gov.uk/ (accessed on 11 June 2021). 
34. Joint Nature Conservation Committee. Marine Conservation Zone Project. 2010. English Network Guidance. Available online: https: / /jncc.gov.uk/ (accessed on 11 June 2021).

35. Win, N.N.; Hanyuda, T.; Kato, A.; Shmabukuro, H.; Uchimura, M.; Kawai, H.; Tokeshi, M. Global Diversity and Geographic Distributions of Padina Species (Dictyotales, Phaeophyceae): New Insights Based on Molecular and Morphological Analyses. J. Phycol. 2021, 57, 454-472. [CrossRef] [PubMed]

36. Price, J.M.; Tittley, I.; Richardson, W.D. The distribution of Padina pavonica (L.) Lamour. (Phaeophyta: Dictyotales) on British and adjacent European shores. Bull. Br. (Nat. Hist.) Bot. Ser. 1979, 7, 1-67.

37. Herbert, R.J.H.; Ma, L.; Marston, A.; Farnham, W.F.; Tittley, I.; Cornes, R.C. The calcareous brown alga Padina pavonica in southern Britain: Population change and tenacity over 300 years. Mar. Biol. 2016, 163, 1-15. [CrossRef] [PubMed]

38. Carter, P.W. The life history of Padina pavonia I. The structure and cytology of the tetrasporangial plant. Ann. Bot. 1927, 41, 139-149. [CrossRef]

39. Gómez-Garreta, A.; Rull-Lluch, J.; Barceló Martí, M.C.; Ribera Siguan, M.A. On the presence of fertile gametophytes of Padina pavonica (Dictyotales, Phaeophyceae) from the Iberian coasts. Anales del Jardín Botánico de Madrid 2007, 64, 27-33. [CrossRef]

40. Williams, L.J. Studies in the Dictyotaceae. III. The periodicity of the sexual cells in Dictyota dichotoma. Ann. Bot. 1905, 19, 531-560. [CrossRef]

41. Phillips, J.A.; Clayton, M.N.; Maier, I.; Boland, W.; Müller, D.G. Sexual reproduction in Dictyota diemensis (Dictyotales, Phaeophyta). Phycologia 1990, 29, 367-379. [CrossRef]

42. Bogaert, K.; Beecckman, T.; De Clerck, O. Abiotic regulation of growth and fertility in the sporophyte of Dictyota dichotoma (Hudson) J.V. Lamouroux (Dictyotales, Phaeophyceae). J. Appl. Phycol. 2016, 28, 2195-2924. [CrossRef]

43. Roberts, C.M.; Hawkins, J.P.; Fletcher, J.; Hands, S.; Raab, K.; Ward, S. Guidance on the Spacing of Marine Protected Areas in England NECRO37; Natural England: Sheffield, UK, 2010.

44. Hutchins, L.W. The basis for temperature zonation in geographical distribution. Ecol. Monogr. 1947, 17, 325-335. [CrossRef]

45. Brown, J.H. On the relationship between abundance and distribution of species. Am. Nat. 1984, 124, 255-279. [CrossRef]

46. Brown, J.H.; Mehlman, D.W.; Stevens, J.C. Spatial variation in abundance. Ecology 1995, 76, 2028-2043. [CrossRef]

47. Herbert, R.J.H.; Marston, A.; Manley, H.; Farnham, W.F. Distribution of the 'Peacocks Tail' seaweed Padina pavonica on the Isle of Wight. Proc. Isle. Wight. Archaeol. Soc. 2018, 32, 112-119.

48. Boxall, S.R.; Robinson, L.S. Shallow sea dynamics from CZCS imagery. Adv. Space Res. 1987, 7, 37-46. [CrossRef]

49. Guyard, P.H. Effects of Oceanographic Factors in the Mesozooplanktonic Communities of the East Solent and Outer Approaches. Ph.D. Thesis, University of Southampton, Southampton, UK, 2000.

50. North, E.W.; Gallego, A.; Petitgas, P. (Eds.) Manual of Recommended Practices for Modelling Physical—Biological Interactions during Fish Early Life; ICES: Copenhagen, Denmark, 2009; 111p.

51. Fletcher, R.L.; Callow, M.E. The settlement, attachment and establishment of marine algal spores. Br. Phycol. J. 1992, 27, 303-329. [CrossRef]

52. Amsler, C.D.; Reed, D.C.; Michael, N. The microclimate inhabited by macroalgal propagules. Br. Phycol. J. 1992, 27, 253-270. [CrossRef]

53. Wichachurcherd, B.; Liddle, L.B.; Prathep, A. Population structure, recruitment and succession of the brown alga Padina boryana Thivy (Dictyotales, Heterokontophyta), at an exposed shore of Sirinart National Park and a sheltered area of Tang Khen Bay, Phuket Province, Thailand. Aquat. Bot. 2010, 92, 93-98. [CrossRef]

54. Dixon, P.S. Perennation, vegetative propagation and algal life histories, with special reference to Asparagopsis and other Rhodophyta. Bot. Gothoburg. 1965, 3, 67-74.

55. Lima, F.P.; Ribeiro, P.A.; Queiroz, N.; Hawkins, S.J.; Santos, A.M. Do distributional shifts of northern and southern species of algae match the warming pattern? Glob. Chang. Biol. 2007, 13, 2592-2604. [CrossRef]

56. Hawkins, S.J.; Sugden, H.E.; Mieszkowska, N.; Moore, P.J.; Poloczanska, E.; Leaper, R.; Herbert, R.J.H.; Genner, M.J.; Moschella, P.S.; Thompson, R.C.; et al. Consequences of climate-driven biodiversity changes for ecosystem functioning of North European rocky shores. Mar. Ecol. Prog. Ser. 2009, 396, 245-259. [CrossRef]

57. Beattie, A.J.; Hay, M.; Magnusson, B.; de Nys, R.; Smeathers, J.; Vincent, J.F.V. Ecology and bioprospecting. Austral Ecol. 2011, 36, 341-356. [CrossRef]

58. Mineur, F.; Arenas, F.; Assis, J.; Davies, A.J.; Engelen, A.H.; Fernandes, F.; Malta, E.-J.; Thibaut, T.; Nguyen, T.V.; Vaz-Pinto, F.; et al. European seaweeds under pressure: Consequences for communities and ecosystem functioning. J. Sea Res. 2015, 98, 91-108. [CrossRef]

59. Harley, C.D.G.; Anderson, K.M.; Demes, K.W.; Jorve, J.P.m.; Kordas, R.L.; Coyle, T.A. Effects of climate change on global seaweed communities. J. Phycol. 2012, 48, 1064-1078. [CrossRef] 